\title{
Authors' reply: Australian immunisation registers: established foundations and opportunities for improvement
}

L K Chin (chinlitkim@gmail.com)1, N W Crawford ${ }^{2,3,4}$, G Rowles ${ }^{5}$, J P Buttery B $^{1,2,3,6}$

1. Infectious Diseases Unit, Monash Children's Hospital, Melbourne, Australia

2. Surveillance of Adverse Events Following Vaccination In the Community (SAEFVIC), Murdoch Childrens Research Institute, Royal Children's Hospital, Parkville, Australia

3. Department of General Medicine, Royal Children's Hospital, Melbourne

4. Department of Paediatrics, University of Melbourne, Melbourne, Australia

5. Riddell Country Practice, Riddells Creek, Victoria, Australia

6. Department of Paediatrics, Monash University, Clayton, Melbourne, Australia

Citation style for this article:

Chin LK, Crawford NW, Rowles G, Buttery JP. Authors' reply: Australian immunisation registers: established foundations and opportunities for improvement. Euro Surveill. 2012;17(21):pii=20179. Available online: http://www.eurosurveillance.org/ViewArticle.aspx?Articleld=20179Article submitted on 21 May 2011 / published on 24 May 2012

We welcome the insight of Sheridan et al. regarding the potential for the Australian Childhood Immunisation Register (ACIR) to be utilised for public health benefit in data linking, not only for examining vaccine safety, but also vaccine effectiveness. Jurisdictional studies have shown the value of this methodology in evaluating the effectiveness of a nationally-funded rotavirus programme within Queensland and Central Australia $[1,2]$. Gold et al. were also able to demonstrate the feasibility of ACIR data linkage in a single hospital study evaluating measles-mumps-rubella vaccine and thrombocytopenia [3].

In Australia, while federal and jurisdictional privacy laws are potential impediments, ethical arguments support data linking for vaccine surveillance as a public health imperative [4]. In addition, the vast majority of the public, when consulted, supported this process [5]. A computer-assisted telephone interview of randomly-selected rural and metropolitan households in South Australia in 2011 found $96.4 \%$ of respondents supported data linkage for post-licensure surveillance of vaccines. Notably, opt-out consent (40.4\%) or no consent needed (30.6\%) was favoured over opt-in consent $(24.6 \%)[5]$.

In a country which traditionally has been an early adopter of vaccines, and allocates national programme funding based upon cost-effectiveness assessments, it is critical that both post-licensure safety and effectiveness can be assessed comprehensively and in a timely fashion [6]. This will maximise protection of vaccine recipients, confidence in the immunisation programme, and allow appropriate allocation of taxpayer resources. Linkage of national immunisation datasets with health outcome data offers a powerful public health resource.
References

1. Snelling TL, Andrews RM, Kirkwood CD, Culvenor S, Carapetis JR. Case-control evaluation of the effectiveness of the G1P[8] human rotavirus G2P[4] infection in Central Australia. Clin Infect Dis. 2011;52(2):191-9

2. Field EJ, Vally H, Grimwood K, Lambert SB. Pentavalent rotavirus vaccine and prevention of gastroenteritis hospitalizations in Australia. Pediatrics. 2010;126(3);e506-12.

3. Gold M, Dugdale S, Woodman RJ, McCaul KA. Use of the Australian Childhood Immunisation Register for vaccine safety data linkage. Vaccine. 2010;28(26):4308-11.

4. Berry JG, Ryan P, Gold MS, Braunack-Mayer AJ, Duszynski KM; for the Vaccine Assessment Using Linked Data (VALiD) Working Group. A randomised controlled trial to compare optin and opt-out parental consent for childhood vaccine safety surveillance using data linkage. J Med Ethics. 2012 Apr 19. [Epub ahead of print].

5. Berry JG, Gold MS, Ryan P, Duszynski KM, Braunack-Mayer AJ; For the Vaccine Assessment Using Linked Data (VALiD) Working Group. Public perspectives on consent for the linkage of data to evaluate vaccine safety. Vaccine. 2012 Apr 27. [Epub ahead of print].

6. Mitchell AS, Isaacs D, Buttery J, Viney R. Funding of drugs: do vaccines warrant a different approach? Lancet Infect Dis. 2009;9(5):269-70; author reply 270-1. 